\title{
UN RETRATO DE GÉRAD EN EL MUSEO DE HUESCA: NUEVA ATRIBUCIÓN Y REINTERPRETACIONES DEL CONTEXTO DE SU PRODUCCIÓN ${ }^{1}$
}

Este artículo propone un cambio en la atribución de autoría y en la identificación del personaje retratado en un cuadro que formaba parte del legado fundacional de Valentín Carderera al Museo de Huesca.

Palabras clave: Devéria; Gérard; Retrato; Luis Felipe; Romanticismo; Francia.

The author proposes both a change of attribution and identification of the sitter for a portrait that formed part of the founding bequest by Valentín Carderera to the Museum of Huesca.

Key words: Devéria; Gérard; Portrait; Louis Philippe; Romanticism; France.

El legado fundacional de Valentín Carderera, a partir del cual se creó la colección del Museo de Huesca, no sólo es muy revelador de los gustos del coleccionista, uno de los personajes más destacados del romanticismo artístico español, sino también del carácter de espejo de valores

\footnotetext{
${ }^{1}$ Mi agradecimiento al Museo de Huesca y al Museo de Versalles, por todas las facilidades y documentación que me han proporcionado, especialmente a María Paz Cantero y Roland Bossard, respectivamente.
} 
cívicos que, para la sociedad decimonónica, había de tener un buen museo. No es casual que, tratándose de un hombre tan piadoso y apasionado estudioso del patrimonio eclesiástico, abunden en su selección los antiguos cuadros religiosos, pero sobre todo llama la atención la importante cantidad de retratos históricos o modernos de personalidades ilustres que destinó al museo, quizá no tanto, o no sólo, por su calidad artística, sino sobre todo por su valor iconográfico y ejemplarizante. Uno de ellos es el que es objeto de estas líneas, en cuyo bastidor escribió seguramente el propio Carderera "Para el M. de Huesca", y que lleva escrito a pincel en el reverso del lienzo "Baron Gérard/pintado por él mismo" (fig. 1) Se trata de un cuadro al óleo de $53 \times 45 \mathrm{~cm}$, realizado con tan escasa densidad pictórica que en algunos lugares hasta queda a la vista el dibujo preparatorio, y en otros presenta problemas de conservación (caídas de la capa de color en la ceja del retratado), destacando el tratamiento abocetado de las pinceladas (sobre todo en la nariz y ojos), todo lo cual parece indicar que se trata de un apunte o estudio preparatorio. De hecho, en el catálogo del Museo de Huesca publicado en 1882 se afirmaba "Es estudio de la cabeza del mismo para el famoso cuadro de la entrada de Enrique IV en París"2.

Verdaderamente, esa otra pintura a la que se alude como posible referencia es una de las más famosas de François Gérard, discípulo predilecto de David que llegó a convertirse en rival de su maestro como retratista, pues en la primera década del siglo XIX posaron para él innumerables personalidades, aunque siempre tuvo a gala denominarse peintre d'histoire ${ }^{3}$ y en esta especialidad su obra cumbre fue sin duda La entrada de Enrique IV en París. Es un prototipo de cuadro propagandístico de la monarquía restaurada, encargado por Luis XVIII en 1816 para exaltar la moderación y el respeto a las normas vigentes por parte de los Borbones, que fue presentado con gran éxito en el Salon de 1817 (coincidiendo con el segundo aniversario de la entrada de Luis XVIII en París), utilizándose después para decorar las estancias regias del palacio de las Tullerías y del Museo Carlos X en el Louvre hasta que, cuando Luis Felipe de Orleáns creó el Musée Historique de Versailles, se convirtió en uno de los principales atractivos de la Galerie des Batailles $^{4}$. No hubiera sido descabellado que el artista se hubiera atrevido a pintarse a sí mismo en aquel acontecimiento histórico, pues es costumbre ancestral de los artistas autorretratarse en algún personaje secundario de algún cuadro que perciben como una obra maestra, y concretamente en el siglo XIX hubo bastantes pintores franceses que, siguiendo el ejemplo de Rafael en el fresco de La Escuela de Atenas, hicieron guiños a su propio mundillo artístico cuando representaban grupos de personajes pretéritos, retratándolos con sus propios rasgos o los de otros artistas coetáneos amigos suyos 5 . Pero, ni hay referencia alguna a ello en la detallada explicación del

\footnotetext{
${ }^{2}$ Catálogo de los objetos que contiene el Museo Provincial de Huesca, a cargo de la Comisión de Monumentos Históricos y Artísticos, Huesca, Imprenta y Lit. de la Viuda e hijos de Castanera, 1882, p. 16, n. ${ }^{\circ} 35$ de catálogo.

${ }^{3}$ Su primer biógrafo, Charles Lenormant, incluso puso esta denominación en el título de su estudio: François Gérard, peintre d'histoire: essai de biographie et de critique. París: Adolphe René et compagnie, 1847 (2. ed.). Más tardías son las biografías escritas por Adolphe VIOLLET-Le-DuC y por Henri GérARD, sobrino del artista y compilador de dos antologías de cartas dirigidas al pintor por otros artistas y celebridades de su tiempo (fueron un éxito editorial decimonónico, probablemente bien conocido por el propio Valentín Carderera, cosa que explicaría su particular aprecio por este cuadro y su decisión de legarlo al Museo de Huesca).

${ }^{4}$ Este cuadro sigue expuesto en el Museo de Versalles, pero existe también una versión más reducida pintada por el propio Gérard, que fue adquirida en 1830 por Carlos X y se conserva en el Museo Municipal de Chartres, así como un estudio preparatorio regalado por el artista a la Duquesa de Berry (también pintó bocetos y otras versiones reducidas, algunas de las cuales han salido a la venta en los últimos años). Ha sido reproducido en numerosos libros sobre arte del siglo XIX y objeto de un pormenorizado estudio monográfico por parte de KAUFMANN, Ruth: "François Gérard's 'Entry of Henry IV into Paris': The Iconography of Constitutional Monarchy”, The Burlington Magazine, vol. CXVII, n. ${ }^{\circ} 873$ (diciembre 1975), pp. 790-802.

${ }^{5}$ Cf. Bonnet, Alain: Artistes en groupe La représentation de la communauté des artistes dans la peinture du XIXe siècle. Rennes, Presses Universitaires de Rennes, 2007.
} 


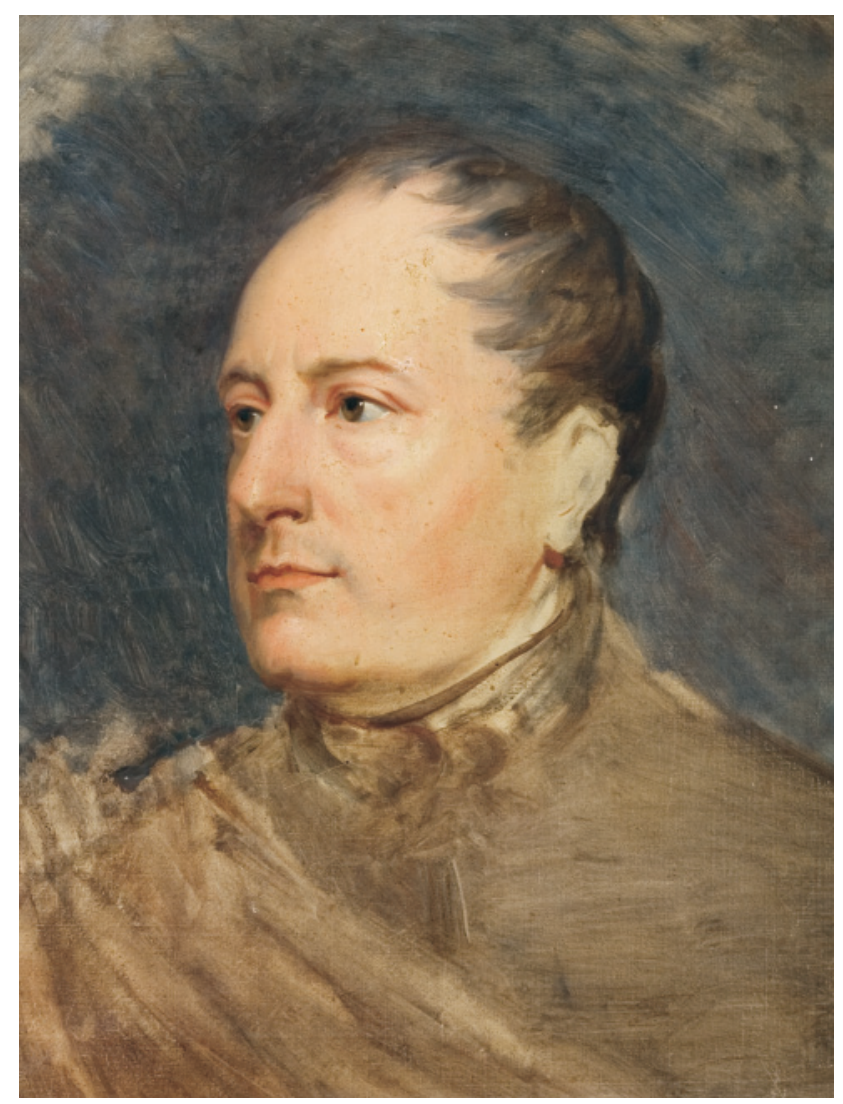

Fig. 1. Retrato de Gérard, Museo de Huesca (Foto de Fernando Alvira, Museo de Huesca).

cuadro que se publicó cuando se dio a conocer al público por primera vez ${ }^{6}$, ni por mucho que miremos ese famoso lienzo de Gérard hallaremos allí su propio retrato, o el de algún personaje que se parezca al del retrato propiedad del Museo de Huesca.

Esta última puntualización se hace necesaria al comparar dicha efigie con la iconografía conocida del artista, que ofrece considerables diferencias a partir de las cuales es difícil seguir identificando el hombre allí representado con el pintor François Gérard. Aunque hay un Musée Gérard en Bayeux, es en el propio Museo de Versalles donde se encuentra su retrato más conocido, pintado en 1824 por Thomas Lawrence donde aparece con la mano derecha sobre el corazón y el rostro de medio perfil, con ademán heroico enfatizado por el peinado de la rala cabellera, extendida coquetamente hacia adelante, según moda napoleónica a la cual debió de ser fiel muchos años después del fin de Bonaparte porque le encubría un poco su alopecia ${ }^{7}$ (fig. 2). No era el único defecto físico que debía esconder, pues el pintor inglés disimuló gracias al ángulo elegido para la pose la curva ganchuda de la nariz, que sí había figurado muy a la vista en su figura de perfil plasmada

${ }^{6}$ Notice historique sur le tableau représentant l'entrée de Henri IV dans Paris, par M Gérard, Membre de l'Institut, de l'Académie des Beaux-Arts, Chevalier de l'Ordre du Roi, et de l'Ordre Royal de la Legión d'Honneur, etc. Paris: Delaunay, Libraire au Palais-Royal, 1817.

7 Sir Thomas Lawrence: François Simon, baron Gérard, âgé de 54 ans, óleo/lienzo, $58 \times 70 \mathrm{~cm}, 1824$, Musée National du Château de Versailles et des Trianons, Versalles. 
en su juventud por Louis-Léopold Boilly en su famoso retrato colectivo de 1798 titulado Reunión de artistas en el taller de Isabey ${ }^{8}$, siendo todavía más resaltada en retratos de madurez, como el retrato de riguroso perfil que en 1830 le realizó David d'Angers para uno de sus medallones dedicados a bustos de artistas ilustres ${ }^{9}$, o en el que dibujó Marie-Éléonore Godefroid en 1835 con idéntico punto de vista ${ }^{10}$. Por último, en lugar de la barbilla prominente que tiene el protagonista del retrato conservado en el Museo de Huesca también se observa una mandíbula bastante más corta en esos retratos de Gérard, lo mismo que en el retrato de medallón pintado sobre marfil que le hizo la miniaturista Lizinka Aimée Zoé de Mirbe ${ }^{11}$ o en otro posterior, aunque sea un retrato idealizado que le representa más joven, publicado en Le Magasin pittoresque en 1839 (se trata de un grabado, de autor desconocido). En todo caso, un detalle importante que tienen en común todos estos retratos del pintor Gérard es que lleva siempre pañuelo blanco anudado al cuello y una especie de abrigo o levita negra; mientras que el personaje del cuadro oscense no tiene tal pañuelo y parece lucir una especie de casaca militar, a juzgar por las insignias doradas que se adivinan en el cuello de la misma. Por tanto, probablemente no se trata del pintor François Gérard, ni tampoco será un artista, pues entre los muchos tipos de retratos de artistas que proliferaron en el siglo XIX ${ }^{12}$ los hay con atuendos formales $\mathrm{y}$, sobre todo, informales, o incluso disfrazados, pero no era concebible posar para una pintura como militar, sin serlo ${ }^{13}$.

Con todo, la información recogida hace más de cien años en el mencionado catálogo del museo altoaragonés puede que no haya supuesto al fin y al cabo una falsa pista. Justo al lado del gran cuadro histórico de Gérard, puede contemplarse en el museo de Versalles otro de parecidas dimensiones titulado El rey Luis Felipe jurando mantener la Carta Otorgada de 1830, en presencia de las cámaras reunidas en el Palais Bourbon, el 9 de agosto de 1830. Es obra de Eugène Devéria, uno de los principales representantes del romanticismo francés, que tuvo una gran reputación por cuadros de tema histórico como éste, encargado en 1834 por Luis Felipe para su Musée Historique: son innumerables los personajes que allí aparecen representados, muchos de los cuales posaron para el artista en los dos años de trabajo que le supuso, dándolo por terminado en 1836 cuando, una vez firmado y fechado, lo entregó al rey, quien, como muestra de su satisfacción y aprecio, le pagó un $20 \%$ más de lo que habían convenido ${ }^{14}$. No sería exagerado

\footnotetext{
${ }^{8}$ Louis-Léopold BoILly: Réunion d'artistes dans l'atelier d'Isabey, óleo/lienzo, 71,5 × $111 \mathrm{~cm}, 1798$, Musée du Louvre, París. François Gérard aparece en el centro del grupo izquierdo, sentado de perfil, absorto en el examen de un lienzo colocado sobre el caballete. Existe un estudio preparatorio de su retrato, sin variaciones respecto a la versión final: Portrait de François Gérard, óleo/lienzo, $46 \times 38$ cm, 1798, Lille, Musée des Beaux-Arts.

9 Pierre-Jean David D'Angers: Baron François Géard, bajorrelieve en bronce, $18 \mathrm{~cm}$ de diámetro, 1830, Angers, Musée David d'Angers.

${ }^{10}$ Marie-Éléonore Godefroid: François Pascal Simon Gérard, à 65 ans. Ilustración en la página 208 del ya mencionado libro de GÉRARD, Henri y Viollet-Le-Duc, Adolphe: Correspondance de François Gérard: peintre d'histoire, avec les artistes et les personnages célèbres de son temps. Paris: Adolphe Lainé et J. Havard (gracias a google books es consultable por internet, en: http://books.google.com/books?id=I14GAAAAQAAJ\&pg=PA208-IA3).

11 Lizinka Aimée ZoÉ DE Mirbel: Portrait du baron Gérard, pintura en medallón de marfil, París, Musée du Louvre. 2007.

12 GuIllén, Esperanza: Retratos del genio. El culto a la personalidad artística en el siglo XIX. Madrid, Cátedra,

${ }^{13} \mathrm{Ni}$ siquiera quienes fueron nombrados académicos, como Gérard, ilustre miembro del Institute de France desde 1812 y luego oficial de la Legión de Honor, lo cual no dejaba de ser una orden militar. Quienes por lo visto sí vistieron la casaca de académicien (con sus decoraciones doradas en cuello, solapas y puños) fueron los camareros de Le Chat Noir, un café-cantante que funcionó entre 1881 y 1897 en Montmartre, pero era un sarcasmo que dio lugar a muchas caricaturas, no a retratos serios.

${ }^{14}$ Gaehtgens, Thomas W., Versailles, de la résidence royale au Musée Historique. La Galerie des Batailles dans le Musée Historique de Louis-Philippe, Amberes, Albin Michel, 1984. VerCIER, Paul: "Les frères Debería et Versailles", Versalia, Revue de la Société des Amis de Versailles, n. ${ }^{\circ} 6$ (2003), 108-123. DAvID, Vincent: Eugène Devéria: La peinture et l'histoire et Eugène Devéria: Variations sur les genres artistiques, París, Réunion des Musées Nationaux, 2005.
} 


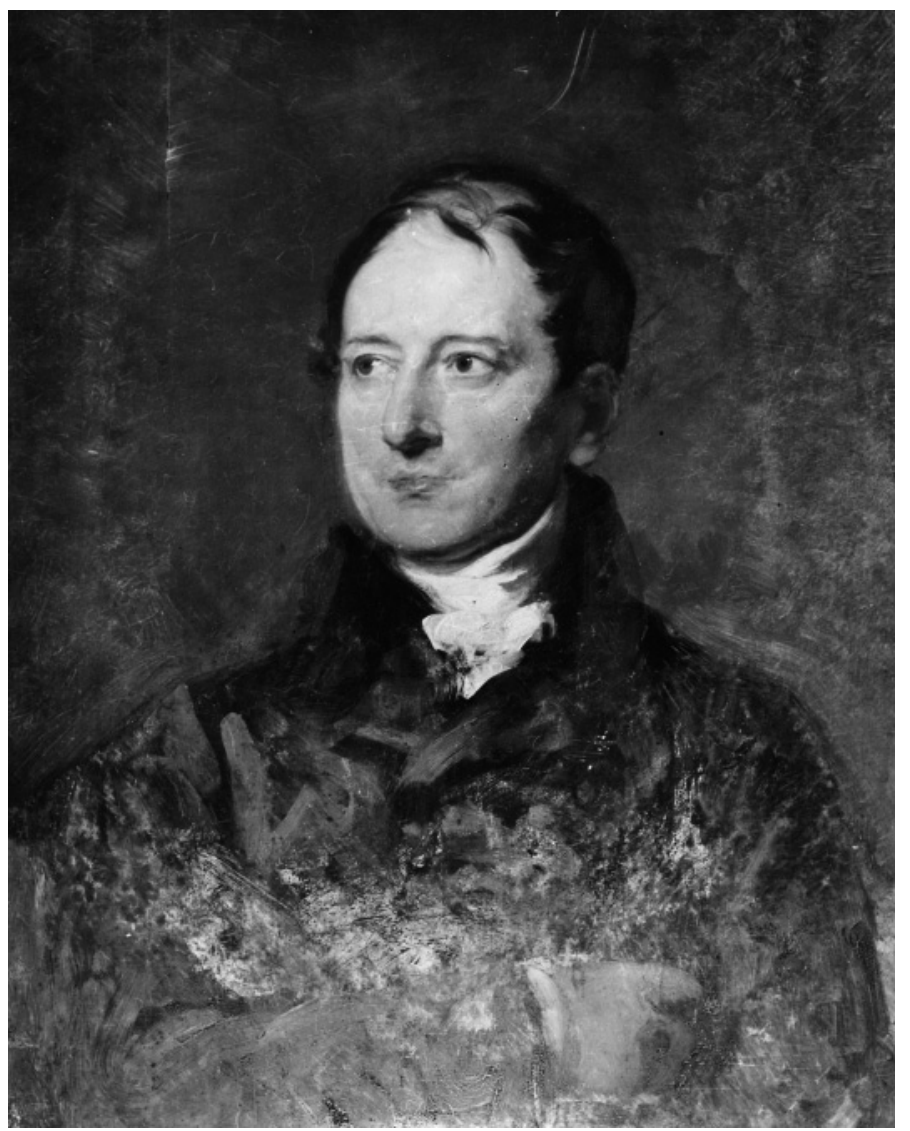

Fig. 2. Retrato del barón Gérard, por Thomas Lawrence, Musée Historique Versailles (Foto Museo Versalles).

comparar ese cuadro con el que David había pintado de la Consagración de Napoleón como Emperador, pues en ambos casos se trataba de ensalzar a un monarca y a su corte, plasmando un acontecimiento político sucedido unos pocos años antes, con vistoso detallismo y aparente fidelidad histórica, de la que parecen dar fe las numerosos personalidades inmortalizadas como testigos de aquellos eventos. Eso sí, el simbolismo político de ese gran cuadro es radicalmente opuesto al que David había pintado sobre la autocoronación de Napoleón en Notre Dame, pues el Rey-Ciudadano no se coronó a sí mismo ante el Papa en una catedral, sino que juró la carta constitucional ante en el Parlamento y el Senado reunidos. Pero su monarquía constitucional no dejaba de ser una sociedad muy estamental, como queda bien reflejado en dicho cuadro, por el lugar protocolario que ocupa en él cada uno de sus innumerables personajes.

Por tanto, su composición no obedece a cánones artísticos ni a la creatividad del pintor, sino sobre todo a la etiqueta cortesana. Es conocida la reacción de Luis Felipe cuando visitó el taller de Devéria y le hizo repintar toda la comitiva que le rodeaba para que colocase su figura más alta que la de ninguno de sus súbditos, salvo las damas y demás familiares que observan desde una logia. En honor a la verdad histórica, no pintó en ella a la reina Amélie, que no estuvo presente (mientras que David sí tuvo que retratar en la logia superior de su cuadro a la madre de Napoleón, a pesar de que todo el mundo sabía que no había querido asistir a su entronización); pero la veracidad histórica seguía sujeta a ciertas conveniencias, como en tiempos de Bonaparte. De 


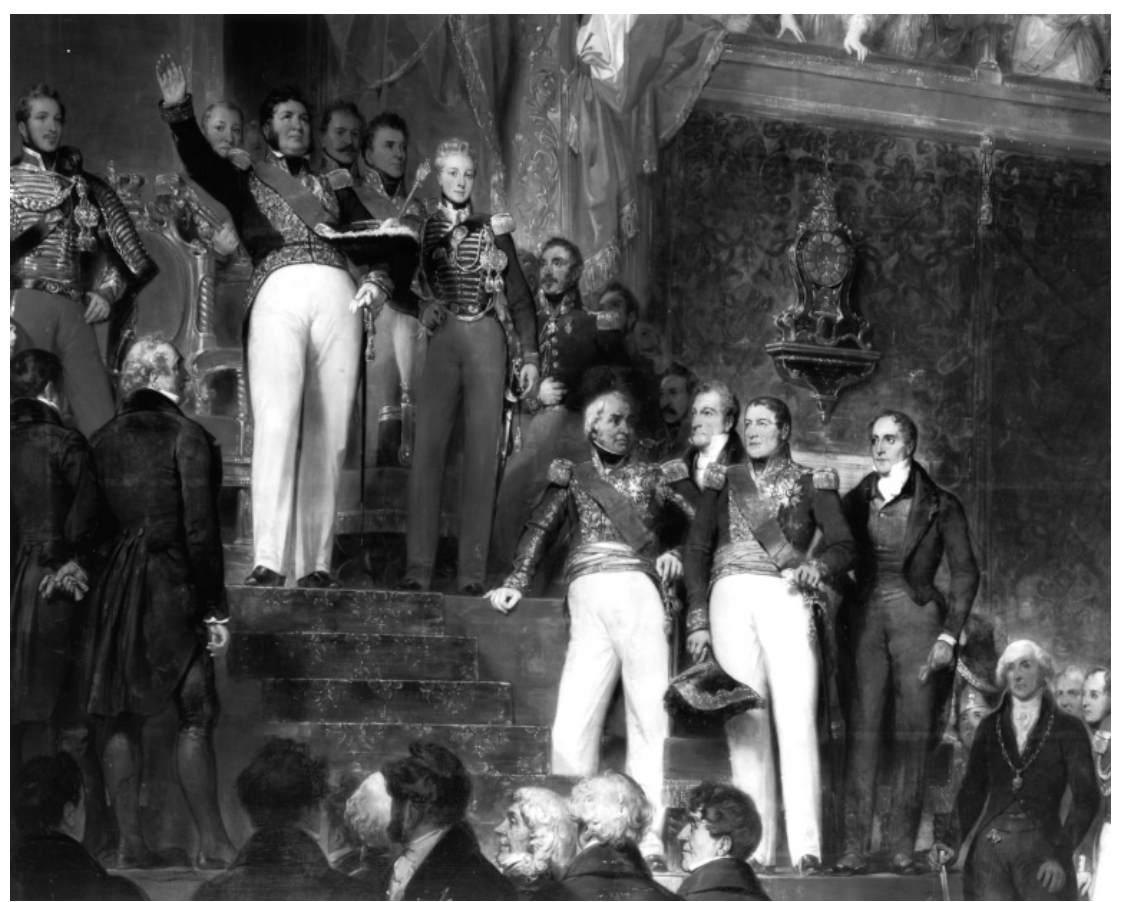

Fig. 3. El rey Luis Felipe jurando la Carta Otorgada (detalle central del cuadro) por Eugène Devéria, Musée Historique Versailles (Foto Museo Versalles).

la misma forma que muchos pagaron a David para aparecer inmortalizados en su consagración imperial ocupando un buen puesto, es de suponer que los jerifaltes que posaron para Devéria también le presionarían de una forma u otra. A la vista de las diferencias entre la versión definitiva del cuadro y el boceto previo más reducido, que también se conserva en Versalles, uno de los que más consiguieron mejorar en protagonismo fue el general Étienne Maurice Gérard, mariscal de Francia y conde de Gérard (fig. 3). En la versión definitiva aparece justo en el centro de la composición, en medio de un grupo de cuatro próceres situados en una grada a los pies del rey, retratado de cuerpo entero (destacando sobre el pantalón blanco su casaca militar y el sombrero de gala que lleva en la mano, en un gesto similar al de su retrato pintado por David en 1816, conservado en el Museo Metropolitano de Nueva York), mientras en el estudio preparatorio aparecía de burgués, asomando sólo la cabeza detrás de las otras tres figuras de ministros.

Dado el evidente parecido, puede afirmarse que el caballero de uniforme retratado en el cuadro de Huesca es este mismo conde de Gérard al que finalmente se le dedicó tanta atención en el gran cuadro del juramento de Luis Felipe. Teniendo en cuenta la vecindad de este cuadro con el dedicado a Enrique IV en la instalación museográfica de la Galerie des Batailles, y la casi homonimia de los protagonistas, resulta fácil comprender la confusión en que cayó la memoria de Valentín Carderera, o la de quienes le proporcionaron la información sobre este retrato. Tampoco es muy grave el cambio de atribución, pues Eugène Devéria es un artista tan importante como François Gérard, y ni siquiera hay necesidad de cambiar el título en la ficha catalográfica, pues a fin de cuentas no deja de ser una semblanza de Gérard, si bien habrá que especificar que no se trata del pintor con título de barón, sino del general con título de conde.

Pero el hecho de que se trate de un óleo sobre lienzo hace de este cuadrito de Huesca un caso especial entre los muchos estudios preparatorios que Devéria realizó para representar el juramento de Luis Felipe u otras grandes composiciones históricas. En los museos de Pau, ciudad del 


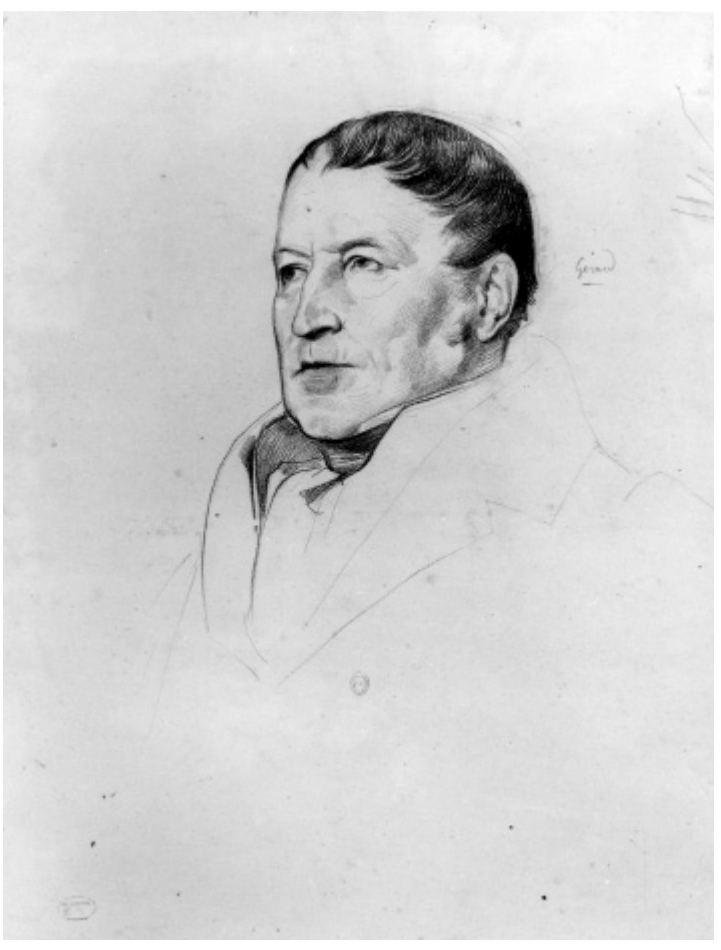

Fig. 4. Retrato a lápiz del conde Gérard, por Eugène Devéria, Bibliothèque Nationale de France (Foto Biblioteca Nacional, París).

otro lado de los Pirineos donde este pintor romántico se estableció al final de su vida, se conservan muchos cuadros suyos y bocetos o dibujos sobre papel, algunos de los cuales puede que sean retratos preparatorios para el gran cuadro de Versalles, como lo son, con toda seguridad, los ochenta retratos a lápiz guardados en la Biblioteca Nacional de París, aproximadamente del mismo tamaño que el cuadrito de Huesca (tienen entre 56 y $58 \mathrm{~cm}$ de alto $\times 42$ a $44 \mathrm{~cm}$ de ancho), entre los cuales hay uno que es un retrato de busto del conde Gérard (lleva una sumaria identificación a la derecha, donde pone: "Gérard") (fig. 4). En dicho dibujo se representan las solapas de una levita que, como queda dicho más arriba, es la indumentaria civil con la que aparecía en la primera versión general del cuadro encargado por Luis Felipe. Tampoco luce en ese dibujo ninguna banda cruzada sobre el pecho, que sí llevan todos los militares pintados en el cuadro definitivo de Devéria, la cual se intuye también en el retrato de Huesca. Si en este caso el artista en vez de limitarse a trazar del natural un dibujo preparatorio o a realizar bocetos sobre cartón (como hizo en lo referente a otros detalles del gran cuadro histórico), se tomó el trabajo de dedicar a este personaje el retrato al óleo sobre lienzo conservado en Huesca, seguramente sería por el cambio de indumentaria y, sobre todo, por el mayor protagonismo que fue cobrando su figura en la versión definitiva del cuadro.

Lejos de ser detalles anecdóticos, estos cambios hasta ahora nunca subrayados en los estudios sobre el gran cuadro del juramento constitucional de Luis Felipe, corresponden a una importante novedad en su contexto de producción, que precisamente queda puesto de manifiesto gracias al lienzo de Huesca. Quizá en 1830 el conde Gérard, entonces Ministro de Guerra, no había figurado en posición muy relevante durante el juramento del rey ante las cámaras, pero cuando cuatro años más tarde se le encargó a Devéria inmortalizar aquel acontecimiento con sus pinceles no sólo había vuelto a ser Ministro de Guerra sino además presidente del Consejo de Ministros. Vivía entonces su momento de máxima gloria militar, tras una victoriosa campaña bélica en Bélgica contra las invasiones holandesas y, por su parte, el propio régimen del Rey Ciudadano se estaba escorando hacia derroteros conservadores, apoyándose cada vez más en los militares. Bien patente queda esto en la evolución de este cuadro-manifiesto, pues la versión reducida de 1834 presenta al rey jurando ante los miembros del gobierno, del Parlamento y del Senado, todos ellos vestidos de civil; mientras que en la gran versión final de 1836 destacan entre las levitas negras algunos atuendos militares, sobre todo el del conde Gérard, en el centro geométrico de la composición.

JEsús PEDRo LoRente Universidad de Zaragoza 